\title{
The role of histamine in implantation in the rabbit
}

\author{
S. K. Dey, C. Villanueva, S. M. Chien and R. D. Crist \\ Department of Gynecology and Obstetrics and Ralph L. Smith Human Development Research \\ Center, University of Kansas Medical Center, Kansas City, Kansas 66103, U.S.A.
}

\begin{abstract}
Summary. When disodium cromoglycate, an inhibitor of histamine release, was instilled into the uterine lumen on Days 5 or 6 of pregnancy, the number of blastocysts implanting was significantly $(P<0.002)$ reduced. Simultaneous instillation of histamine and disodium cromoglycate prevented the effect.
\end{abstract}

\section{Introduction}

The role of histamine in implantation in rats has been a subject of considerable research interest. Some results indicate that histamine release from the uterus as a result of oestrogen stimulation may be an important factor for blastocyst implantation (Shelesnyak, 1957; Spaziani \& Szego, 1958; Spaziani \& Szego, 1959; Ferrando \& Nalbandov, 1968). This assumption is strengthened by the following observations. (1) Histamine content and mast cell population are reduced in rat uteri subjected to freezing, and blastocyst implantation cannot be induced by local oestrogen instillation into previously frozen uteri (Ferrando \& Nalbandov, 1968). (2) Implantation does occur after uterine freezing when histamine is infused into the same uterus (Ferrando \& Nalbandov, 1968). (3) An antagonist of histamine, pyrathiazine, prevents implantation when instilled into the uterus (Shelesnyak, 1957). Studies of mice also indicate the involvement of histamine in implantation in this species (Saksena, Lau \& Chang, 1976). However, to our knowledge, no work has been reported on the role of histamine in implantation in the rabbit. We have investigated the involvement of histamine in rabbit implantation by using an inhibitor of histamine release by mast cells, disodium cromoglycate (Brogden, Speight \& Avery, 1974).

\section{Materials and Methods}

Experiment 1. On Days 4, 5 or 6 of pregnancy (Day $1=24$ h post coitum), rabbits were anaesthetized and the uteri were exteriorized. In each rabbit, $0.2 \mathrm{ml} 0.15 \mathrm{M}-\mathrm{NaCl}$ containing $8 \mathrm{mg}$ lactose was instilled into the control horn and $0.2 \mathrm{ml} 0.15 \mathrm{M}-\mathrm{NaCl}$ containing $8 \mathrm{mg}$ disodium cromoglycate which contains an equal amount by weight of lactose (Fisons Ltd) was instilled into the contralateral (experimental) horn. Right and left horns were randomly used for the control or experimental treatment. On Day 12, the does were killed. The uteri and ovaries were examined for the presence of implantation sites and corpora lutea (ovulation points) respectively. The viability of embryos was determined by the presence of a heart beat.

Experiment 2. The rabbits were anaesthetized and laparotomized on Day 5 of pregnancy. A volume of $0.2 \mathrm{ml} 0.15 \mathrm{M}-\mathrm{NaCl}$ was injected into the lumen of one uterine horn (control) and $0.2 \mathrm{ml}$ $0 \cdot 15 \mathrm{M}-\mathrm{NaCl}$ containing $8 \mathrm{mg}$ disodium cromoglycate and $1 \mathrm{mg}$ histamine base (Sigma Chemicals) was injected into the other (experimental). On Day 12, the does were killed and the implantation sites and ovulation points were recorded.

Experiment 3. The uptake of disodium cromoglycate by various tissues was investigated after instillation of the drug into the uterus. On Day 5 of pregnancy $0.2 \mathrm{ml} 0.15 \mathrm{M}-\mathrm{NaCl}$ containing $8 \mathrm{mg}$ $(327.3 \mu \mathrm{Ci}$ ) tritiated disodium cromoglycate (sp. act. $20.95 \mathrm{mCi} / \mathrm{mmol}$ ) (Fisons Ltd) was instilled into one uterine horn (experimental) and the same volume of saline only was placed in the contralateral horn (control). The rabbits were killed on Day 6 and both uterine horns were flushed with $0 \cdot 15 \mathrm{M}-\mathrm{NaCl}$ 
to recover the blastocysts. The blastocysts were rinsed four times with $0 \cdot 15 \mathrm{M}-\mathrm{NaCl}$. The blastocysts, blastocyst washings and uterine flushings were processed for liquid scintillation counting. Radioactivity was also measured in the uteri, ovaries and oviducts from the control and experimental sides, and in blood samples withdrawn before and at 1,2, 4, 6 and $24 \mathrm{~h}$ after $\left[{ }^{3} \mathrm{H}\right]$ disodium cromoglycate instillation. Radioactivity was measured in a liquid scintillation spectrometer (Packard TRI-CARB Model 3385).

\section{Results}

As shown by the results in Table 1 intrauterine instillation of disodium cromoglycate on Days 5 or 6 of pregnancy caused a significant reduction in implantation numbers. Moreover, many of the implantation sites in treated horns were not viable. The number of implantation sites was restored almost to control numbers by instillation of disodium cromoglycate and histamine together (Table 1).

The uptake of $\left[{ }^{3} \mathrm{H}\right]$ disodium cromoglycate by various reproductive tissues and blood from the uterine lumen was studied in 3 rabbits. About $0.4 \%$ of the radioactive compound was found in the systemic circulation $1-6 \mathrm{~h}$ after instillation of the compound and amounts were negligible by $24 \mathrm{~h}$. Radioactivity was not detected in the oviducts and ovaries (either side), in the uterine horn injected with saline, or in 8 blastocysts from 2 control uteri (one control uterus and its 4 blastocysts were not properly processed and were excluded). However, the radioactivity in the 3 uterine horns infused with $\left[{ }^{3} \mathrm{H}\right.$ ]disodium cromoglycate was $226398 \pm 94816$ (s.e.m.) $\mathrm{ct} / \mathrm{min}$ per uterus $(0.04 \pm 0.017 \%)$ and $24944 \pm 14792 \mathrm{ct} / \mathrm{min}$ per blastocyst $(0.005 \pm 0.003 \%, n=15)$. The blastocyst washings and uterine flushings showed no radioactivity. The blastocysts recovered from the control and experimental uterine horns were morphologically normal.

\section{Discussion}

In the rabbit, implantation occurs $6 \frac{1}{2}-7$ days post coitum. The results of the present experiments show that intrauterine instillation of an inhibitor of histamine release (disodium cromoglycate) during Days 5 or 6 of pregnancy affects implantation. The involvement of histamine in the implantation process in rabbits is supported by the observation that the anti-implantation effect of disodium cromoglycate is prevented by simultaneous treatment with histamine. The $8 \mathrm{mg}$ dose of disodium cromoglycate was used in the experiments because smaller doses did not inhibit implantation. This dose should not be considered large because in the rabbit the drug is poorly absorbed by different tissues, is not metabolized and is rapidly excreted from blood (half-life for whole body elimination is $20 \mathrm{~min}$ ) (Ashton et al., 1973).

The mechanism by which disodium cromoglycate interrupts early pregnancy in rabbits is not clear. The drug may inhibit the release of histamine from the uterus and thereby interfere with implantation, or the blastocysts may take up, retain and release disodium cromoglycate at the site of implantation during early embryonic invasion of the endometrium. This local release could then inhibit uterine secretion of histamine and thus prevent implantation. Involvement of the blastocyst is suggested by the observation that the uptake of $\left[{ }^{3} \mathrm{H}\right]$ disodium cromoglycate by the blastocyst is much greater than that by the uterus when total mass, cell populations and the surface areas of the blastocyst and uterus are compared. The continuation of pregnancy after uterine instillation of disodium cromoglycate on Day 4 of gestation suggests that rabbit blastocysts of this age are unable to take up, retain or release the drug or that the drug is cleared from the uterus before the blastocysts can do so.

We thank Dr G. F. Moss, Fisons Ltd, Pharmaceutical Division, England, for the gift of tritiated disodium cromoglycate. The work was supported by the University of Kansas Medical Center Research Committee and in part by USPHS Grant No. HD-02528. We thank Miss Mary Hernandez for typing the manuscript. 


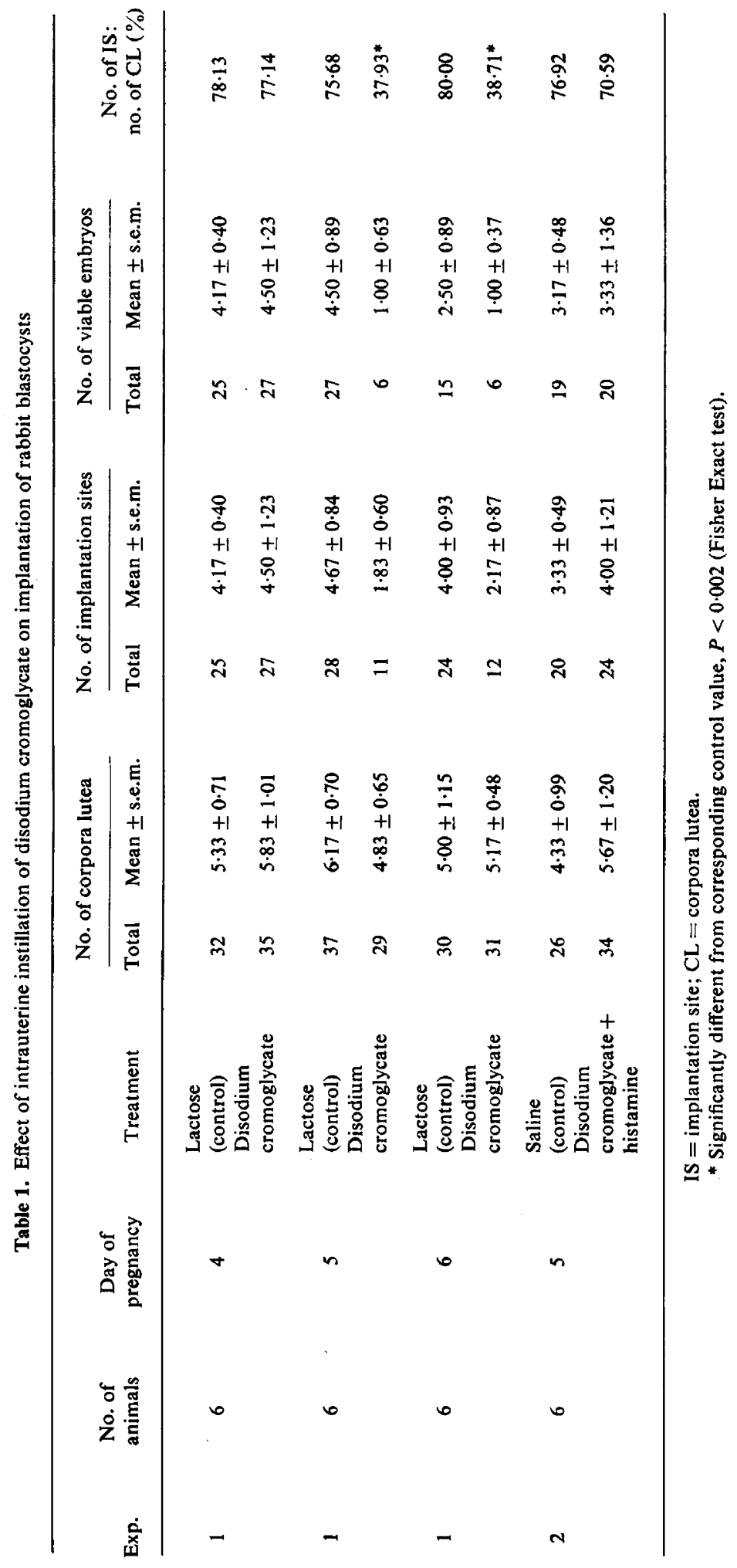




\section{References}

Ashton, M.J., Clark, B., Jones, K.M., Moss, G.F., NeAle, M.G. \& Ritchie, J.T. (1973) The absorption, metabolism and excretion of disodium cromoglycate in nine animal species. Toxic. appl. Pharmac. 26, 319328.

Brogden, R.N., Speight, T.M. \& Avery, G.S. (1974) Sodium cromoglycate: a review of its mode of action, pharmacology, therapeutic efficacy and use. Drugs 7, 164-282.

Ferrando, G. \& Nalbandov, A.V. (1968) Relative importance of histamine and estrogen on implantation in rats. Endocrinology 83, 933-937.

SAKSENA, S.K., LAU, I.F. \& Chang, M.C. (1976) Relationship between estrogen, prostaglandin $F_{2 \alpha}$ and histamine in delayed implantation in the mouse. Acta endocr., Copenh. 81, 801-807.

SheleSNYAK, M.C. (1957) Some experimental studies on the mechanism of ova-implantation in the rat. Recent Prog. Horm. Res. 13, 269-322.

Spaziani, E. \& Szego, C.M. (1958) The influence of estradiol and cortisol on the uterine histamine of the ovariectomized rat. Endocrinology 63, 669-678.

Spaziani, E. \& Szego, C.M. (1959) Further evidence for mediation by histamine of estrogenic stimulation of the uterus. Endocrinology 64, 713-723.

Received 13 June 1977 